\title{
David Jacob
}

\section{Minderheitenrecht in der Türkei}

Recht auf eigene Existenz, Religion und Sprache nichtnationaler Gemeinschaften in der türkischen Verfassung und im Lausanner Vertrag

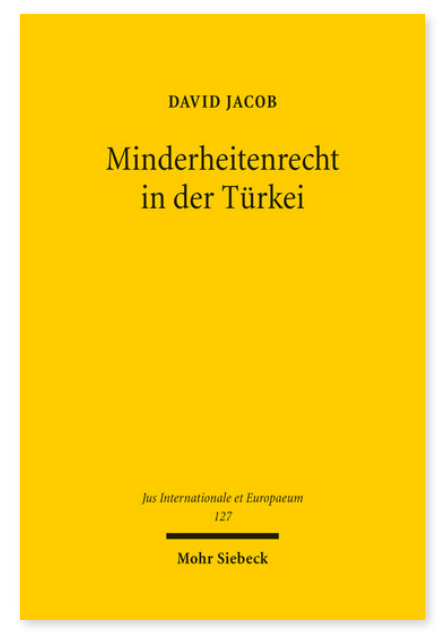

2017. XXVII, 309 Seiten. JusIntEu 127

ISBN 978-3-16-154133-9

DOI 10.1628/978-3-16-154133-9

eBook PDF 79,00€

ISBN 978-3-16-154132-2

fadengeheftete Broschur 79,00€
Der Lausanner Vertrag aus dem Jahr 1923 enthält einen Katalog an Minderheitenrechten, zu denen sich die Türkei verpflichtet hat. Der Katalog kann sich mit den heutigen Standards für Minderheitenrechte messen lassen. Er enthält Rechte auf eigene Existenz, Religion und Sprache. Durch die Ratifizierung des Lausanner Vertrages seitens der Türkei sind die dort enthaltenen Rechte für nichtnationale Gemeinschaften nationales Recht und haben mindestens den Rang von Gesetzen. David Jacob stellt jedoch fest, dass die beiden verfassungsgemäßen Grundsätze der Republik, der Nationalismus und der Laizismus, im Spannungsverhältnis zu den Minderheitenrechten des Lausanner Vertrages stehen. Das Nationalismusprinzip definiert die türkische Nation ethnisch als sunnitische und türkischsprachige Gemeinschaft, das Laizismusprinzip verfolgt das Ziel, den sunnitischen Islam zu kontrollieren und zu fördern. Mit diesen verfassungsmäßigen Merkmalen der Republik sind die verbrieften Rechte des Lausanner Vertrages nicht vereinbar.

David Jacob Geboren 1976; Studium der Rechtswissenschaft in Heidelberg, Mannheim und Barcelona; Promotion (Köln); seit 2006 als Rechtsanwalt tätig.

Jetzt bestellen:

https://mohrsiebeck.com/buch/minderheitenrecht-in-der-tuerkei-9783161541339?no cache=1

order@mohrsiebeck.com

Telefon: +49 (0)7071-923-17

Telefax: +49 (0)7071-51104 